\title{
GROWTH, CARBOHYDRATE PRODUCTIVITY AND GROWTH KINETIC STUDY OF Halochlorella rubescens CULTIVATED UNDER $\mathrm{CO}_{2}$-RICH CONDITIONS
}

\author{
TAN KEAN MENG ${ }^{1}$ and MOHD ASYRAF KASSIM ${ }^{1 *}$ \\ ${ }^{1}$ Bioprocess Technology Division, School of Industrial Technology, \\ Universiti Sains Malaysia, 11800 USM Penang, Malaysia \\ *E-mail: asyrafkassim@usm.my
}

Accepted 3 September 2019, Published online 30 June 2020

\begin{abstract}
This study was parametrically established to investigate the effect of different initial $\mathrm{pH}$ cultivation medium from $\mathrm{pH} 4.00$ to $\mathrm{pH} 10.00$ and $\mathrm{CO}_{2}$ concentration from $0.04 \%$ to $25 \%(\mathrm{v} / \mathrm{v})$ on the growth and carbohydrate content of Halochlorella rubescens. Changes in biochemical compositions were also analysed using Fourier-transform infrared spectroscopy (FTIR). The maximum concentration of biomass and the productivity carbohydrate were $0.49 \pm 0.01 \mathrm{~g} / \mathrm{L}$ and $22.42 \pm 0.03 \mathrm{mg} / \mathrm{L} . \mathrm{d}$ respectively, when $\mathrm{pH} 10.00$ and $5 \%(\mathrm{v} / \mathrm{v}) \mathrm{CO}_{2}$ concentration were used for cultivation. The FTIR analysis revealed obvious changes in the chemical functional groups for the $1200-900 \mathrm{~cm}^{-1}, 1655 \mathrm{~cm}^{-1}$ and $2850 \mathrm{~cm}^{-1}$ bands, which represent carbohydrate, protein and lipid in microalgal biomass under different cultivation conditions. At the completion of this study, two kinetic growth models, Logistic and Gompertz were evaluated for microalgae growth at elevated condition. The kinetic model analysis for Halochlorella rubescens growth at high $\mathrm{CO}_{2}$ condition fit well with the Gompertz equation with $\mathrm{R}^{2}$ value of 0.9977 . The data acquired from this research was helpful for predicting the growth characteristics of microalgae in a $\mathrm{CO}_{2}$-rich medium and could act as an essential platform for the production of chemicals and biofuels.
\end{abstract}

Key words: Microalgal biomass, $\mathrm{pH}, \mathrm{CO}_{2}$ bio-fixation, biochemical compositions, FTIR, kinetic modelling

\section{INTRODUCTION}

Extensive fossil fuel burning for global energy demand has attributed up to $76 \%$ of carbon dioxide gas, $\mathrm{CO}_{2}$ and resulting to the global warming (Sahoo et al., 2012). Subsequently, this effect led to the depletion of fossil fuel reserves, coupled with rising prices and demand for energy, resulting in alternative renewable resources. Global attention has been paid to the production of renewable energy from renewable bioresource such as microalgae. This is due to the capability of this microorganism to exhibit high growth rate over cultivation time (Blinová et al., 2015). In addition, the advantage of $\mathrm{CO}_{2}$ sequestration by microalgae through photosynthesis and biomass could also be converted into a wide range of value-added products (Gong \& You, 2014). It has also been reported that microalgae can accumulate high amount of biochemical compounds such as carbohydrates, proteins and lipids (Caporgno \& Mathys, 2018). According to the

\footnotetext{
* To whom correspondence should be addressed.
}

research conducted by Ho et al. (2012) who reported that microalgae could accumulate high amount of carbohydrate content up $46.7 \%$ relative to other organisms, such as plants. For example, studies have showed that microalgal-carbohydrate can be converted into various types of bioenergy, such as bioethanol, biobutanol, biohydrogen and biogas. Previous research by Chen et al. (2013) proposed the use of microalgae-based carbohydrates as a feedstock for the production of liquid biofuels (i.e., bioethanol and biobutanol) through fermentation process. In addition, another study also demonstrated that an increase green alga carbohydrate content could be beneficial as a feedstock for biogas production (methane and hydrogen) under anaerobic fermentation (Mussgnug et al., 2010). The microalgal-carbohydrate has therefore become a feedstock and has led to an increase in the feasibility of the sustainable biorefinery process (Rosenberg et al., 2011).

Nonetheless, the potential of microalgae was limited a low biomass production rate and carbohydrate productivity (Benedetti et al., 2018). 
Generally, the biomass production rate and carbohydrate productivity in microalgae could be attributed to biotic and abiotic factors under cultivation conditions. Different cultivation parameters such as temperature, $\mathrm{pH}, \mathrm{CO}_{2}$ concentrations, salinity, light intensity, inorganic salt, inoculum volume and nitrogen source have been reported to have a significant effect on the growth rate of microalgae and biochemical production (Kassim et al., 2017, Pires et al., 2012). Among these parameters, $\mathrm{pH}$ and $\mathrm{CO}_{2}$ were reported to be the most crucial parametes that could influence the rate of production of microalgae biomass and carbohydrate prodcutivity ( $\mathrm{Ji}$ et al., 2017; Ying \& Zimmerman, 2014). This was due to the formation of carbonic acid in the cultivation medium when $\mathrm{CO}_{2}$ was supplied into the liquid medium (Tang et al., 2011). Subsequently, the formation of an acidic environment could influence microalgae growth productivity (Vaquero et al., 2014). Also the changes in the cultivation condition will affect the microalgae's extracellular enzyme, which was the key enzyme in the carbon concentrating mechanism (CCM) (Kroumov et al., 2016; Moroney \& Ynalvez, 2007; Tang et al., 2011). Few studies have been conducted related to the interaction of $\mathrm{pH}$ and $\mathrm{CO}_{2}$ with microalgalcarbohydrate. Previous study carried out by Mousavi et al. (2018) found that the increasing accumulation of carbohydrates of Coelastrum sp. $\mathrm{SM}$ up to $17 \%$ is replaced by a concentration of $6 \%$ of the $\mathrm{CO}_{2}$ with a $12 \%(\mathrm{v} / \mathrm{v})$ of $\mathrm{CO}_{2}$. A further increase in the $\mathrm{CO}_{2}$ concentration up to $16 \%(\mathrm{v} / \mathrm{v})$ would have a negative effect on accumulation of carbohydrate. Similar results have been reported by Posadas et al. (2015) who found higher accumulation of carbohydrate up to $61.2 \%$ by Scenedesmus sp. when cultivated with a pure concentration of $\mathrm{CO}_{2}$.

Study of microalgae growth kinetics model is also important to provide a better understanding of the growth of microalgae, particularly under elevated cultivation conditions (Lee et al., 2015). A well-fitted model should be capable of predicting the performance of the microalgae and the productivity of the cultivation system under certain conditions (Darvehei et al., 2018). Appropriate models have been used in the study of microalgae growth and product formation in order to reduce the overall cost of growth production, particularly in the context of large-scale application (Yang et al., 2011). According to the study by Praveen et al. (2018), which showed that different cultivation mode would have different growth model. Previous study by Béchet, et al. (2017) described that the cultivation of Dunaliella salina was well adapted to the Weibull model under high temperature condition. Whereas, Zhang et al. (2015) reported that the Aiba model was well fitted to microbial growth under photo-limitation regime. Therefore, the model selected for this experiment takes into account the interactions between the initial $\mathrm{pH}$ values and the percentage of $\mathrm{CO}_{2}$ on the kinetic growth behavior of microalgae. To date, insufficient information on the growth kinetic model has been reported, particularly at elevated $\mathrm{pH}$ and $\mathrm{CO}_{2}$ concentrations.

It is therefore essential to ensure that the selected microalgae strain is able to withstand high $\mathrm{CO}_{2}$ concentrations in order to maintain a high production rate for biomass and to be easily scaled up for industrial application, particularly in industrial areas (Salih, 2011). On the other hand, many original studies concerned these approaches to the effect of cultivation modes on lipid accumulation in microalgae and provide less supportive information on the productivity of carbohydrates, particularly under $\mathrm{CO}_{2}$-rich conditions (Han et al., 2013; Qiu et al., 2017; Widjaja, 2010). This project was therefore designed to determine the growth rate of microalgae, the productivity of carbohydrate and changes in biochemical compounds during cultivation at different $\mathrm{pH}$ and $\mathrm{CO}_{2}$ concentrations. The appropriate kinetic model for microalgae growth under normal $\left(\mathrm{pH} 8.00\right.$ and $0.04 \%(\mathrm{v} / \mathrm{v}) \mathrm{CO}_{2}$ ) and elevated condition was also determined using Logistic and Gompertz models.

\section{MATERIALS AND METHODS}

\section{Microalgae and cultivation medium}

During the whole study, Halochlorella rubescens freshwater microalgae obtained from the School of Industrial Technology, USM (Penang, Malaysia) was used. The medium used in this study was modified algae growth (MLA) medium consisting of the following chemical compositions (per litre of distilled water): $0.49 \mathrm{~g} \mathrm{MgSO}_{4} \cdot 7 \mathrm{H}_{2} \mathrm{O}$, $1.70 \mathrm{~g} \mathrm{NaNO}_{3}, 0.14 \mathrm{~g} \mathrm{~K}_{2} \mathrm{HPO}_{4}$ and $0.03 \mathrm{~g} \mathrm{CaCl}_{2} .2 \mathrm{H}_{2} \mathrm{O}$. The medium was sterilised using a $0.22 \mu \mathrm{m}$ Millipore filter (Eroglu et al., 2013).

A standardised $10 \%(\mathrm{v} / \mathrm{v})$ initial cell concentration of $0.29 \mathrm{~g} / \mathrm{L}$ equivalent to the optical density (OD) $688 \mathrm{~nm}$ at 1.00 with a volume of $70 \mathrm{~mL}$ was cultivated in $1 \mathrm{~L}$ of Schott bottle containing $700 \mathrm{~mL}$ of modified MLA (Li et al., 2019). The relationship with the concentration of cells was determined by the correlation between the absorbance value at $688 \mathrm{~nm}$ and cell dry weight (CDW) (Lu et al., 2017). On the basis of the following equation the cell concentration of microalgae was calculated:

$\mathrm{CDW}_{\text {Chlorella sp. }}=0.2845\left(\mathrm{OD}_{680 \mathrm{~nm}}\right)+0.0016 ; \mathrm{R}^{2}=0.9739$ 
The cell concentration was estimated at $4500 \mathrm{rpm}$ at $15 \mathrm{~min}$ by centrifuged $50 \mathrm{~mL}$ of aliquots cell. Then the empty tube and pellet tube was dried in an oven at $60^{\circ} \mathrm{C}$ was weighed.

The cultures were maintained at $28 \pm 2.0^{\circ} \mathrm{C}$ with initial $\mathrm{pH}$ value of $\mathrm{pH} 7.95 \pm 0.02$. The cultivation medium was adjusted to $\mathrm{pH} 4.00,6.00,8.00$, and 10.00 respectively using $0.1 \mathrm{M}$ of sodium hydroxide $(\mathrm{NaOH})$ or hydrochloric acid (HCL) solution with the aided of $\mathrm{pH}$ metre. A flowrate of $0.3 \mathrm{~L} / \mathrm{min}$ using different $\mathrm{CO}_{2}$ concentrations $(0.04,5,15$ and $25 \%$ $(\mathrm{v} / \mathrm{v})$ balanced compressed air) was consistently provided to the culture. Besides, the cultures were illuminated with a photon intensity of $20 \mu \mathrm{mol} / \mathrm{m} / \mathrm{s}$ and a photoperiod cycle of $12 \mathrm{~h}: 12 \mathrm{~h}$ (light:dark). The microalgae were harvested by centrifuged at $4500 \mathrm{rpm}$ at $15 \mathrm{~min}$ at the late exponential phase. The pellet was rinsed twice with distilled water to remove unwanted salt and dried overnight at $60^{\circ} \mathrm{C}$ until constant weight was reached. The dried pellet was used for subsequent analysis. To minimise the sampling and measurement error, each experiment was performed in triplicate.

\section{Growth kinetics}

Cell growth was measured on a daily basis from Day 0 until Day 10 of cultivation using spectrophotometer with OD $688 \mathrm{~nm}$. Absorbance measurement were done in triplicates. The concentration of cells was predicted using the calibration curve of $\mathrm{OD}_{688 \mathrm{~nm}}$ to the concentration of microalgae cells $(\mathrm{g} / \mathrm{L})$.

The microalgal biomass productivity $(\mathrm{P})$ and specific growth rate $(\mu)$ were calculated to monitor the microalgae growth performance under specific conditions

$$
\begin{gathered}
\mathrm{P}=\frac{X_{f}-X_{0}}{T_{f}-T_{0}} \\
\mu=\frac{\ln X_{f}-\ln X_{0}}{t_{f}-t_{0}}
\end{gathered}
$$

where $\mathrm{P}$ is microalgal biomass productivity $(\mathrm{mg} /$ L.d), $\mu$ is the specific growth rate $\left(\mathrm{d}^{-1}\right), \mathrm{X}_{\mathrm{f}}$ is cell concentration $(\mathrm{g} / \mathrm{L})$ at a time $\mathrm{t}_{\mathrm{f}}$ (days) and $\mathrm{X}_{0}$ is initial cell concentration $(\mathrm{g} / \mathrm{L})$ at time $\mathrm{t}_{0}$ (days).

\section{Determination of carbohydrate content}

Total carbohydrate analysis was based on the method of phenol-sulfuric acid method (Nielsen, 2010). Approximately 50mg dry cell was suspended from hydrochloric acid $(\mathrm{HCl})$ and incubated in a water bath at $90^{\circ} \mathrm{C}$ for 3 hours. The mixture was neutralised by the addition of sodium carbonate
$\left(\mathrm{Na}_{2} \mathrm{CO}_{3}\right)$ and diluted to $50 \mathrm{~mL}$ with distilled water. The mixture was centrifuged at $3000 \mathrm{rpm}$ for 15 minutes in order to separate the solid residues and the dissolved sugar. Then exactly $0.2 \mathrm{~mL}$ of the supernatant was diluted to $1.0 \mathrm{~mL}$ with distilled water. The solution was added with $1.0 \mathrm{~mL}$ of $5 \%$ phenol solution and $5 \mathrm{~mL}$ of $96 \%$ sulphuric acid. Subsequently, the mixture was kept in the water bath at $30^{\circ} \mathrm{C}$ for 30 minutes before the OD $485 \mathrm{~nm}$ was analysed. For this carbohydrate analysis, dextrorotatory (D) $(+)$ glucose was used as a standard. The analysis was performed in triplicate for each sample.

The carbohydrate content (\%) and productivity (mg/L.d) was calculated based on the following equation:

Carbohydrate content $(\%)=\frac{\mathrm{C}}{\mathrm{V}} \times \mathrm{M}$

Carbohydrate Productivity $=\mathrm{C} \times \mathrm{P}$

where $\mathrm{C}$ is the carbohydrate content $\left(\mathrm{mg} \mathrm{mL}^{-1}\right), \mathrm{V}$ is the volume of the supernatant, $\mathrm{M}$ is the total volume $(\mathrm{mL})$ of the microalgae sample solution and $\mathrm{P}$ is microalgal biomass productivity (mg/L.d).

\section{FT-IR spectra}

FTIR was used to analyse microalgae biomass $(\sim 0.1 \mathrm{mg})$ in dried state with potassium bromide $(\mathrm{KBr})$ aided for lamination purpose. Samples were collected by at least 32 numbers as spectra with a resolutions of $4 \mathrm{~cm}^{-1}$. Murdock and Wetzel (2009) described the details of these bands in relation to specific functional groups.

\section{Kinetic model}

The basic Logistic equation and Gompertz equation were adopted in this research to predict the kinetic behaviour of microalgal growth. The selection of an appropriate model with $\mathrm{R}^{2}>0.95$ showed that the kinetic growth of the microalgae fitted well with the suggested model.

Logistic model: $\quad \mathrm{C}(\mathrm{t})=\frac{\text { co eut }}{1-\left(\frac{C o}{C m}\right)(1-e \mu t)}$

Gompertz model: $C(t)=C_{0} * e\left[-e\left(\mu * e^{1 / c o}\right)\right] *\left(C_{m}-t\right)+1$

where $\mathrm{C}_{0}$ is the initial Halochlorella rubescens biomass $(\mathrm{g} / \mathrm{L})$; $\mathrm{Cm}$ is the maximum biomass $(\mathrm{g} / \mathrm{L})$; $\mu$ is the specific growth rate $\left(\mathrm{day}^{-1}\right)$ and $t$ is the cultivation time (day).

\section{Statistics}

All results were expressed in triplicate to calculate the mean \pm standard error. In order to be considered statistically significant, a value of $\mathrm{P}<$ 0.05 was performed using Minitab 16 software. 


\section{RESULTS AND DISCUSSION}

\section{Effect of pH on growth rate and carbohydrate productivity}

One of the critical factors affecting microalgal growth and its carbohydrate productivity is the initial cultivation $\mathrm{pH}$ for microalgae. Lise et al. (2007) reported that the $\mathrm{pH}$ variation in the cultivation medium could affect not only the rate of $\mathrm{CO}_{2}$ uptake, but also the processes of membrane transport and the metabolic function involved in the regulation of cellular $\mathrm{pH}$.

Figure 1(a) shows that the maximum biomass concentration for Halochlorella rubescens was $0.41 \pm 0.01 \mathrm{~g} / \mathrm{L}$ from the cultivation medium using initial value of $\mathrm{pH} 10.00$. Whereas, cultivation using pH 4.00 shows the lowest growth rate of $0.24 \mathrm{~d}^{-1}$ and biomass concentration of $0.34 \pm 0.02 \mathrm{~g} / \mathrm{L}$ (Table 1). The increase in the growth rate of microalgae during cultivation at $\mathrm{pH} 10.00$ is due to the absorption of carbon into the cell which has assisted the photosynthesis and the growth rate of microalgae (Tang et al., 2011). Similar results have been reported by Cortés et al. (2018) who showed the wild-type Dictyosphaerium chlorelloides (Dc1Mwt) grew well in $\mathrm{pH} 9.00$ with highest specific growth rate of $2.17 \pm 0.24 \mathrm{~d}^{-1}$ during days 15 cultivation compared to other $\mathrm{pH}$ values. Whereas the opposite effect was observed in the previous study, which found that Coccomyxa onubensis had the highest cell density in the acidic environment, $\mathrm{pH} 4.00$ (Vaquero et al., 2014). The cultivation beyond optimum condition was found to reduce microalgae growth rate. The statistical analysis (result not shown) of the maximum biomass concentration shows a significant variation $(\mathrm{P}<0.05)$ between the four different initial $\mathrm{pH}$ cultivation values. This indicates that due to good growth at $\mathrm{pH}$ values of 10.00 this microorganism can be characterised as alkali-tolerant microalgae.

Table 1 shows that the maximum productivity of carbohydrate was $18.30 \pm 0.03 \mathrm{mg} / \mathrm{L} . \mathrm{d}$ obtained from the cultivation medium using the initial $\mathrm{pH}$ value of 10.00 . While, the minimum productivity of carbohydrate was $5.56 \pm 0.01 \mathrm{mg} / \mathrm{L} . \mathrm{d}$ obtained from the $\mathrm{pH} 8.00$. Increasing the productivity of carbohydrates at $\mathrm{pH} 10.00$ could be attributed to the secretion of extracellular polysaccharides and the conversion of other chemical compounds such as proteins and lipids into carbohydrates under specific cultivation conditions (Fan et al., 2015; Taraldsvik \& Myklestad, 2000). These results coincided with the previous study, which showed that the Chlorella vulgaris microalgae stimulated higher carbohydrate


Fig. 1. (a) Halochlorella rubescens growth profile at different initial $\mathrm{pH}$ value (b) Carbohydrate content and productivity at different initial $\mathrm{pH}$ values using $0.04 \% \mathrm{CO}_{2}$ concentration. Data were reported as means of triplicates \pm standard error. Means with different letter are significantly different (One-way ANOVA (unstacked), $\mathrm{p}<0.05$ ).

Table 1. Kinetic parameters of Halochlorella rubescens at different initial $\mathrm{pH}$ values of $0.04 \% \mathrm{CO}_{2}$ concentrations

\begin{tabular}{lcccc}
\hline $\mathrm{pH}$ & 4.00 & 6.00 & 8.00 & 10.00 \\
\hline Specific growth rate $\left(\mathrm{d}^{-1}\right)$ & 0.24 & 0.25 & 0.25 & 0.26 \\
Maximum biomass concentration (g/L) & $0.34 \pm 0.02$ & $0.40 \pm 0.01$ & $0.39 \pm 0.01$ & $0.41 \pm 0.01$ \\
Overall biomass productivity (mg/L.d) & $30.69 \pm 0.02$ & $36.54 \pm 0.01$ & $35.50 \pm 0.01$ & $37.81 \pm 0.01$ \\
Carbohydrate content (\%) & $23.51 \pm 0.56$ & $33.12 \pm 3.28$ & $15.68 \pm 1.25$ & $48.41 \pm 2.81$ \\
Carbohydrate productivity (mg/L.d) & $7.21 \pm 0.00$ & $12.10 \pm 0.03$ & $5.56 \pm 0.01$ & $18.30 \pm 0.03$ \\
\hline
\end{tabular}


content when treated with $\mathrm{pH} 9$ and $\mathrm{pH} 5$ compared to normal condition, pH 7 (Al-Safaar et al., 2016). This results therefore clearly showed that cultivation $\mathrm{pH}$ has an important influence on the growth and carbohydrate productivity of microalgae.

\section{Effect of different $\mathrm{CO}_{2}$ concentrations on growth rate and carbohydrate productivity}

Microalgae cultivation was conducted in the range of $0.04 \%$ to $25 \%$ to study the extent of the effect of $\mathrm{CO}_{2}$ concentrations on Halochlorella rubescens growth and its carbohydrate productivity. Figure 2(a) illustrates that Halochlorella rubescens grows well in the alkaline medium with $\mathrm{CO}_{2}$ concentrations ranging from $0.04 \%$ to $15 \%$. It was observed that maximum concentration of biomass with specific growth rate up to $0.49 \pm 0.01 \mathrm{~g} / \mathrm{L}$ and $0.26 \mathrm{~d}^{-1}$ was achieved when supplied with $5 \%(\mathrm{v} / \mathrm{v})$ $\mathrm{CO}_{2}$ concentration. This result was higher compared to the Vidyashankar et al. (2013), which showed only $0.137 \mathrm{~d}^{-1}$ under $15 \% \mathrm{CO}_{2}$ condition using the microalgae strain Scenedesmus dimorphus. The increased concentration of $\mathrm{CO}_{2}$ improved the microalgae growth rate can be well explained by the photosynthetic microalgae growth requiring a supply of $\mathrm{CO}_{2}$ as a source of carbon. According to Yang and Gao (2003), who explained that increased $\mathrm{CO}_{2}$ concentration could increase carboxylating activity while repressing Rubisco's oxygenating activity, resulting in increased photosynthesis and microalgae growth rate. In addition, Dubinsky (1986) also showed that $\mathrm{CO}_{2}$ enrichment could enhance photosynthetic electron transport between photosystem (PS) II and PS I, in which algae growth was highly attributed. Based on previous study, it showed that significant increase in the specific growth rate of $C$. vulgaris UMACC 001 when cultivated under $0.075 \%(\mathrm{v} / \mathrm{v}) \mathrm{CO}_{2}$ rich condition (Teoh et al., 2013).
However, microalgae cultivation above the stated concentration of $\mathrm{CO}_{2}$ such as $25 \%$ was found to produce lower concentration of microalgae biomass and specific growth rate up to $55.10 \%$ and $15.38 \%$ compared to concentration of $5 \%(\mathrm{v} / \mathrm{v}) \mathrm{CO}_{2}$. High $\mathrm{CO}_{2}$ concentration may be explained to induce low $\mathrm{pH}$ and low carbonic anhydrase activity, which will subsequently inhibit microalgae growth (Tang et al., 2011). These findings are comparable to the study conducted by Chinnasamy et al. (2009) which indicated that Chlorella vulgaris ARC 1 microalgae had a low specific growth rate and a concentration of biomass when cultivated at a high $\mathrm{CO}_{2}$ concentration $(20 \%)$. These results were further reinforced by a statistical analysis showing that the maximum biomass concentration of Halochlorella rubescens has significant difference $(\mathrm{P}<0.05)$ between the four different $\mathrm{CO}_{2}$ concentrations using $\mathrm{pH} 10.00$ as the initial $\mathrm{pH}$ value for cultivation (result not shown). This indicates that the cultivation of microalgae at different $\mathrm{CO}_{2}$ concentrations will contribute to the microalgal growth rate.

Table 2 indicates that the maximum and minimum for carbohydrate productivity were 22.42 $\pm 0.03 \mathrm{mg} / \mathrm{L} . \mathrm{d}$ and $16.44 \pm 0.02 \mathrm{mg} / \mathrm{L}$.d when the cultures were supplied with $5 \%$ and $25 \% \mathrm{CO}_{2}(\mathrm{v} / \mathrm{v})$ respectively. Increasing the carbohydrate content from $0.04 \%$ to $25 \% \mathrm{CO}_{2}(\mathrm{v} / \mathrm{v})$ increased the photosynthesis rate and consequently increased the production of starch and glucose (Lv et al., 2010). However, a further increase in the concentration of $\mathrm{CO}_{2}$ up to $25 \%(\mathrm{v} / \mathrm{v})$ would have a detrimental effect on microalgae cells and would subsequently reduce the productivity of carbohydrate. Therefore, it is indicated that Halochlorella rubescens microalgae are categorised as a $\mathrm{CO}_{2}$ tolerant type of microalgae due to their capability to grow in elevated $\mathrm{CO}_{2}$ conditions. The microalgae that can

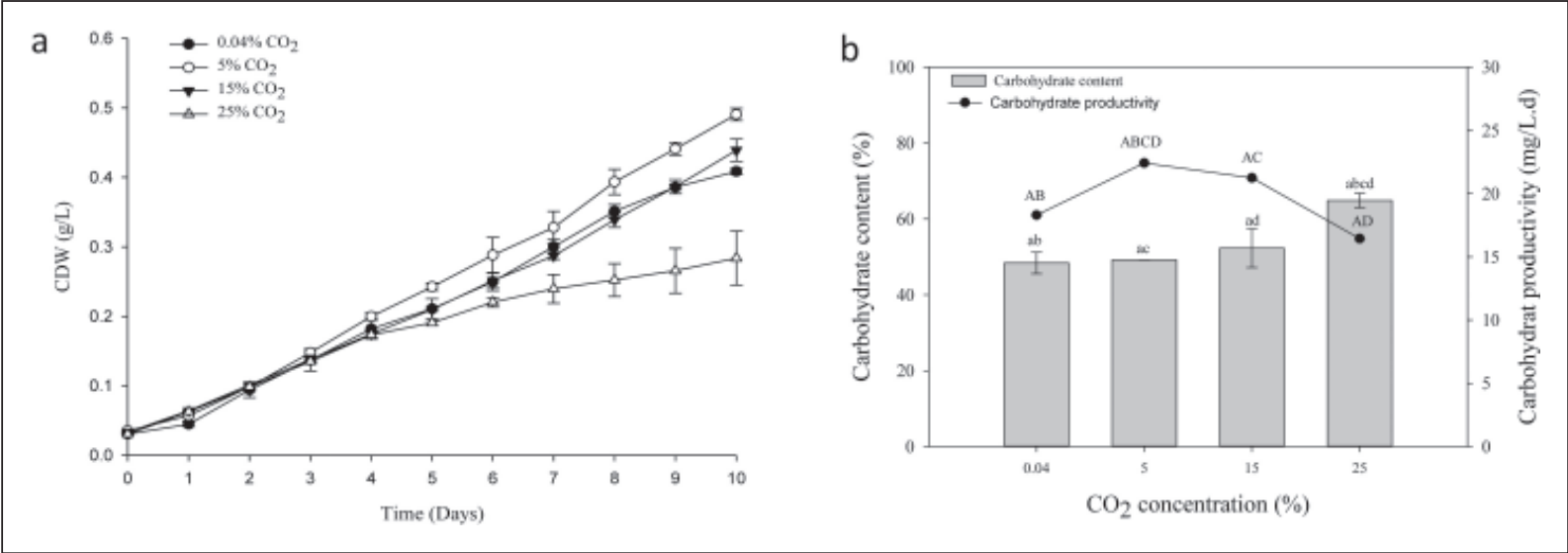

Fig. 2. (a) Halochlorella rubescens growth profile at different $\mathrm{CO}_{2}$ concentrations (b) Carbohydrate content and productivity at different $\mathrm{CO}_{2}$ concentrations using $\mathrm{pH} 10.00$ as initial $\mathrm{pH}$ cultivation. Data were reported as means of triplicates \pm standard error. Means with different letter are significantly different (One-way ANOVA (unstacked), $\mathrm{p}<0.05$ ). 
Table 2. Kinetic parameters of Halochlorella rubescens at different $\mathrm{CO}_{2}$ concentrations using $\mathrm{pH} 10.00$ as initial $\mathrm{pH}$ values for microalgae cultivation. Cultivation was performed at temperature $28 \pm 2{ }^{\circ} \mathrm{C}$ and photoperiod $12 \mathrm{~h}$ : $12 \mathrm{~h}$ (light: dark)

\begin{tabular}{lcccc}
\hline $\mathrm{pH}$ & \multicolumn{4}{c}{10.00} \\
\hline $\mathrm{CO}_{2}$ concentration (\%) & 0.04 & 5 & 15 & 25 \\
Specific growth rate & 0.26 & 0.26 & 0.26 & 0.22 \\
Maximum biomass concentration (g/L) & $0.41 \pm 0.01$ & $0.49 \pm 0.01$ & $0.44 \pm 0.02$ & $0.22 \pm 0.04$ \\
Overall biomass productivity (mg/L.d) & $37.81 \pm 0.01$ & $45.56 \pm 0.01$ & $40.62 \pm 0.02$ & $25.35 \pm 0.04$ \\
Carbohydrate content (\%) & $48.41 \pm 2.81$ & $49.21 \pm 0.02$ & $52.30 \pm 5.08$ & $64.87 \pm 1.89$ \\
Carbohydrate productivity (mg/L.d) & $18.30 \pm 0.01$ & $22.42 \pm 0.03$ & $21.24 \pm 0.01$ & $16.44 \pm 0.02$ \\
\hline
\end{tabular}

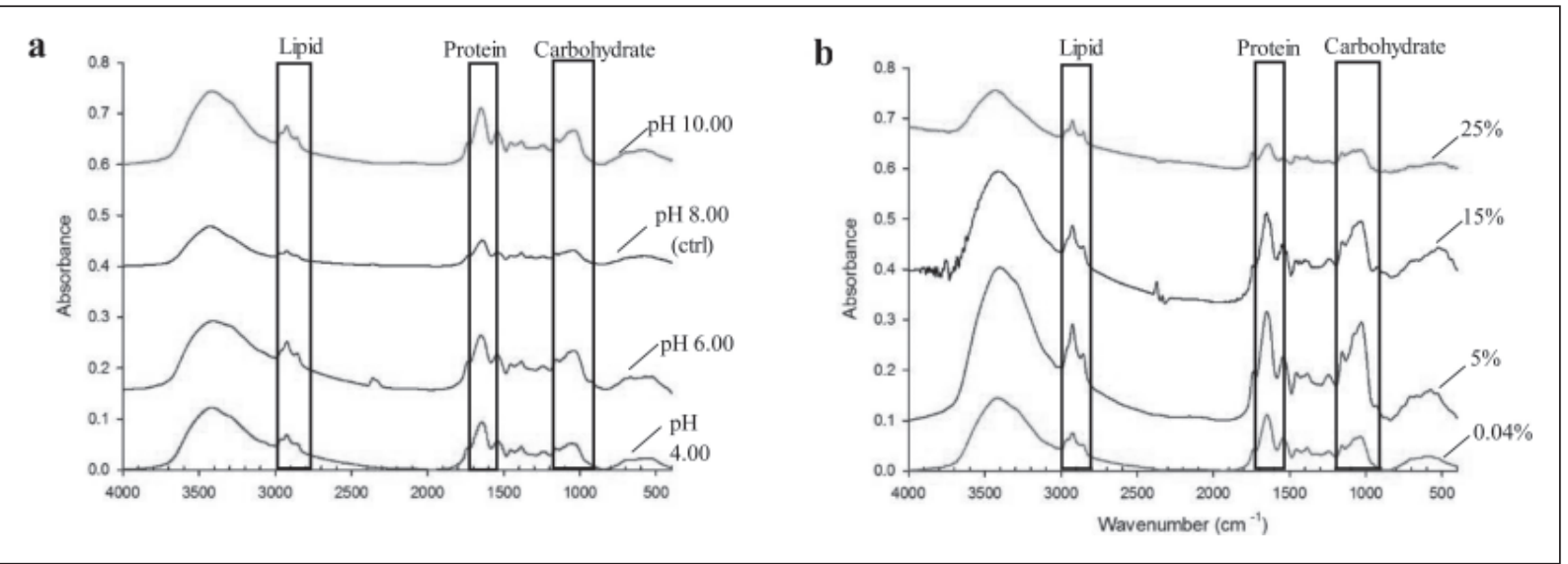

Fig. 3. FTIR spectra of Halochlorella rubescens cultivated at different conditions (a) $\mathrm{pH}$ (b) $\mathrm{CO}_{2}$ concentrations.

grow in high $\mathrm{CO}_{2}$ have great potential to be applied in $\mathrm{CO}_{2}$ capture for $\mathrm{CO}_{2}$ released from industries activity especially the natural gas combined with cycle plant industry $\left(3-6 \% \mathrm{CO}_{2}\right)$ and while it also can accumulate high amount of carbohydrate which become an important platform for chemical and biofuel production (Last \& Schmick, 2011).

\section{FTIR spectrum}

The qualitative change and the functional group in microalgae biomass under the elevated conditions are identified using FT-IR spectroscopy and the spectra are collected over the wavenumbers ranging between 4000-400 $\mathrm{cm}^{-1}$ (Figure 3).

Figure 3(a) and (b) spectrum show that peaks at region $3000-2800 \mathrm{~cm}^{-1}$ have increased significantly in band intensity by up to $141.74 \%$ corresponding to the lipid content of microalgal biomass when cultivation shifts from $\mathrm{pH} 8.00$ to $\mathrm{pH} 10.00$. Similar result was seen in Figure 3(b) when cultivation was carried out using 5\% instead of $0.04 \%(\mathrm{v} / \mathrm{v})$ of $\mathrm{CO}_{2}$ concentration ( $\mathrm{Yu}$ et al., 2019). This phenomenon can be explained by the activation of the lipid synthesis mechanism in the metabolism of microalgae, which produces large amounts of lipid content, in particular neutral lipids, such as triacylglycerol (TAG), which are then accumulated in microalgal biomass under stress conditions ( $\mathrm{Lv}$ et al., 2010).
Figure 3(a) and (b) also show that there is a significant increase in band intensity at the peak around $\sim 1655 \mathrm{~cm}^{-1}$, which could be the result of the $\mathrm{C}=\mathrm{O}$ stretching vibration corresponding to the protein content of Halochlorella rubescens microalgae (Driver et al., 2015). Based on the results shown in this study, the total protein from microalgae cultivation of in alkaline conditions, $\mathrm{pH}$ 10.00 and $5 \%(\mathrm{v} / \mathrm{v})$ have the highest absorption intensity compared to other cultivation conditions. This is due to the cultivation of microalgae in alkaline condition with $5 \%(\mathrm{v} / \mathrm{v}) \mathrm{CO}_{2}$ concentration can stimulate the highest growth rate and photosynthetic rate, subsequently generating different amino acids in the Krebs cycle through transamination process (Lv et al., 2010). This result was further supported by previous studies who showed that cultivation under high alkaline conditions and $\mathrm{CO}_{2}$ concentration could enhance protein content in microalgae (Qiu et al.,2017).

In addition, Figure 3 (a) and (b) also show significant changes for peaks in the $1200-900 \mathrm{~cm}^{-1}$ region, which is a direct response to the $\mathrm{v}(\mathrm{C}-\mathrm{O}-\mathrm{C})$ stretching vibration corresponding to the carbohydrate component of the microalgae biomass (Yu et al., 2019). Increased band intensity in this region up to $113.06 \%$ was observed when cultivation shift from $\mathrm{pH} 8.00$ to $\mathrm{pH} 10.00$. Similar observations were obtained when the cultivation was 
carried out using $5 \%$ of $\mathrm{CO}_{2}(\mathrm{v} / \mathrm{v})$ concentration. It was found that cultivation at high $\mathrm{CO}_{2}$ concentration could significantly increase the band intensity at this specific region. This phenomenon was due to the increase in the rate of growth and photosynthesis of microalgae, which led to the activation of the carbohydrate biosynthesis pathway in the Calvin cycle (Khairy et al., 2014).

The results of this study therefore provides important information for the chemical and biofuel industries by accumulating different group of chemical compound by adjusting the different initial $\mathrm{pH}$ and $\mathrm{CO}_{2}$ concentrations to the cultivation medium.

\section{Growth kinetic study}

In order to better understand of microalgae growth in different cultivation conditions, the growth kinetic study should be used. The model chosen for this experiment takes into account the interactions between the initial $\mathrm{pH}$ values and the percentage of $\mathrm{CO}_{2}$ on biomass growth of microalgae to predict the kinetic behaviour of microalgae growth. For this specific study, two kinetic growth models where used, including the Logistic and Gompertz model.

Figures 4 (a) and (b) show that the microalgae growth in normal condition $(\mathrm{pH} 8.00$ and $0.04 \%$ $\left.\mathrm{CO}_{2}(\mathrm{v} / \mathrm{v})\right)$ attained a higher $\mathrm{R}^{2}$ value of 0.9969 in the Gompertz model, compared to 0.9935 in the Logistic type model. Similar results were reached by the use of $\mathrm{pH} 10.00$ with $5 \%$ of $\mathrm{CO}_{2}$ to replace normal air when enhanced cultivation was performed. In comparison to the Logistic model for both cultivation conditions (Table 3), the Gompertz model also shows lower value in mean square (MS) residue. The results have also been confirmed by the residual plot shown in Figure 5. The residual plot indicated a difference between the experimental and the predicted values and a good residual plot should a

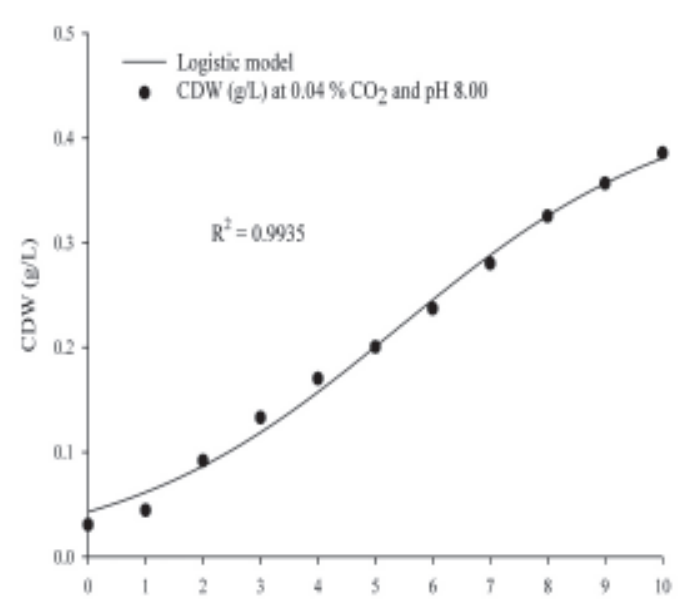

C $\left.{ }^{10.6}\right]$ - Logistic model

- $\mathrm{CDW}(\mathrm{g} / \mathrm{L})$ at $5 \% \mathrm{CO}_{2}$ and $\mathrm{pH} 10.00$

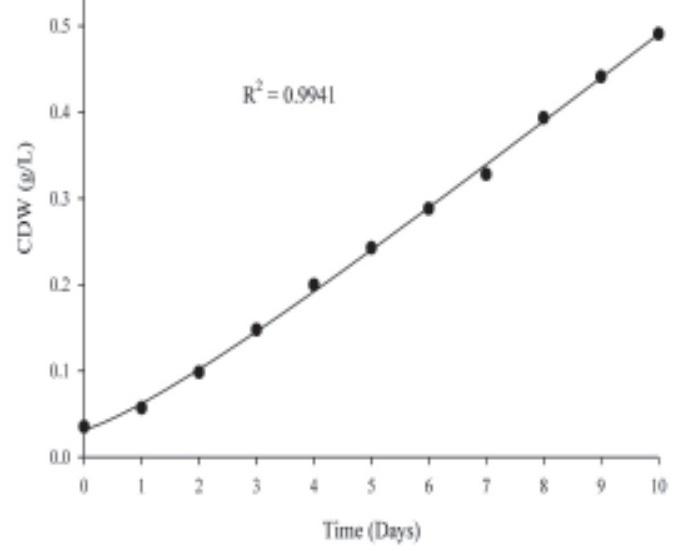

b

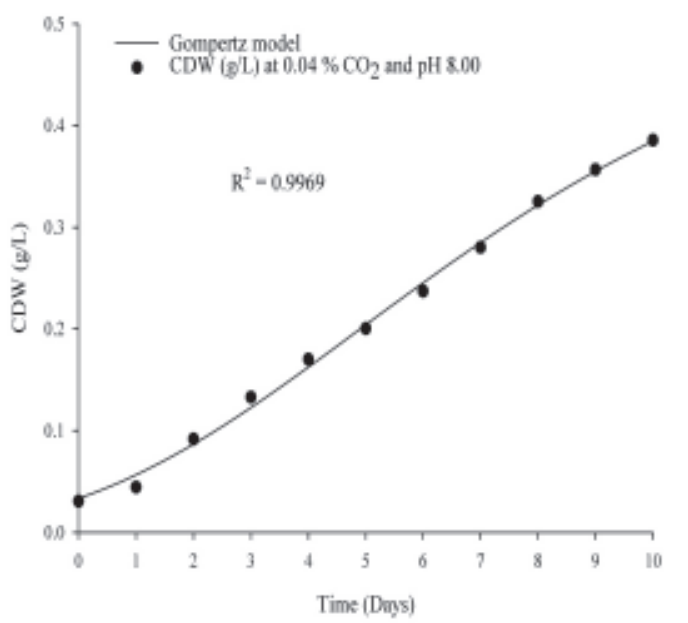

d

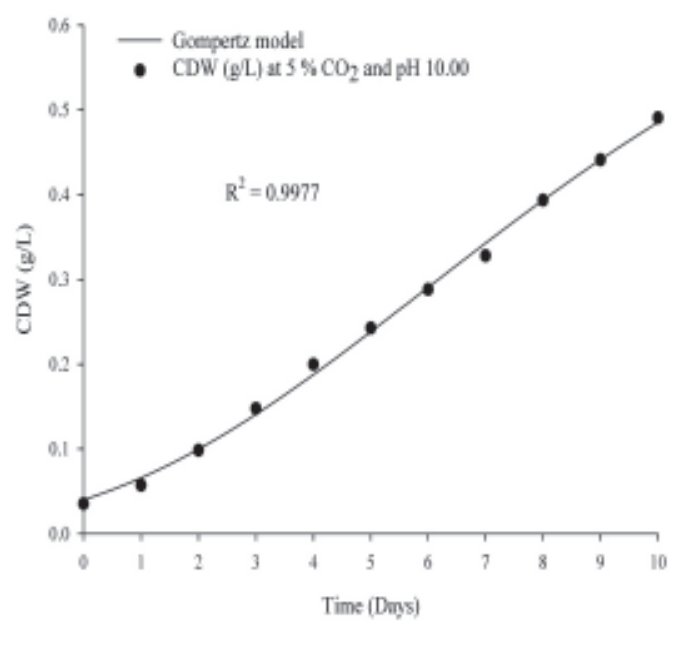

Fig. 4. Halochlorella rubescens cultivated under normal condition ( $\mathrm{pH} 8.00$ and $\left.0.04 \% \mathrm{CO}_{2}(\mathrm{v} / \mathrm{v})\right)($ a) Logistic (b) Gompertz and enhanced condition (c) Logistic (d) Gompertz. 
Table 3. $\mathrm{R}^{2}$ and MS (Residual) of Logistic and Gompertz model

\begin{tabular}{lccccc}
\hline \multirow{2}{*}{ Models } & \multicolumn{2}{c}{$\mathrm{R}^{2}$} & & \multicolumn{2}{c}{ MS (Residual) } \\
\cline { 2 - 3 } \cline { 6 - 6 } \cline { 6 - 6 } & Normal & Enhanced & & Normal & Enhanced \\
\hline Logistic & 0.9935 & 0.9941 & & 0.0099 & 0.0119 \\
Gompertz & 0.9969 & 0.9977 & & 0.0068 & 0.0075 \\
\hline
\end{tabular}

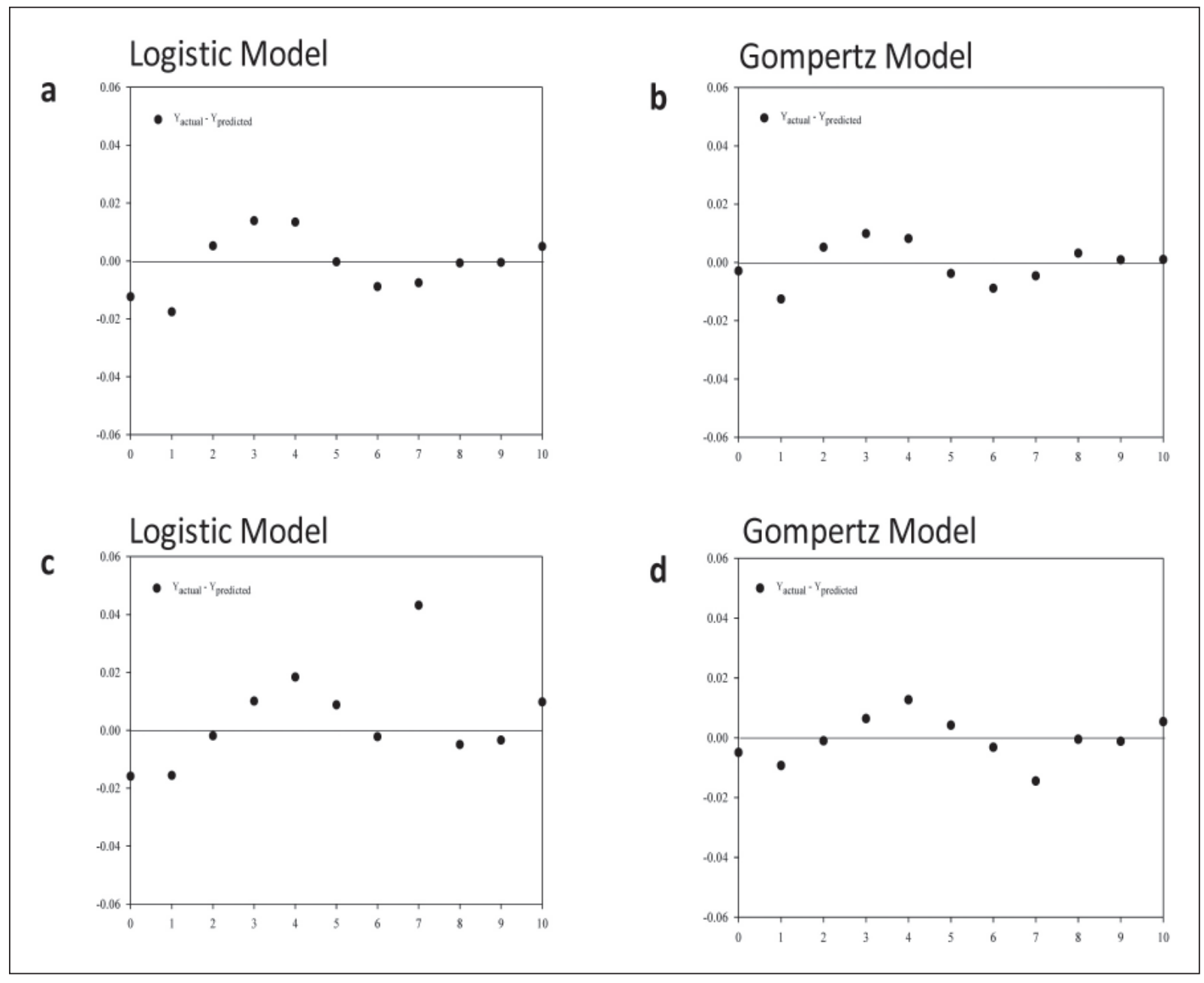

Fig. 5. Residual plots normal condition ( $\mathrm{pH} 8.00$ and $\left.0.04 \% \mathrm{CO}_{2}(\mathrm{v} / \mathrm{v})\right)$ (a) Logistic (b) Gompertz and enhanced condition (c) Logistic (d) Gompertz.

not have randomly distributed patterns, and the values should be close to the X-axis (Filali et al., 2011; Lam et al., 2016). Based on Figure 5, the Gompertz model demonstrates more convergence towards the $\mathrm{X}$-axis compared to the Logistic model under both conditions. This shows that the error of prediction by the Gompertz model is smaller than that of the Logistic model and is acceptable to represent the growth of Halochlorella rubescens in this study. This indicates that the Gompertz model fits well with the experimental microalgae growth data for the cultivation under this specific condition.
The suitability of the Gompertz curve model was further emphasised by a researcher who stated that the Gompertz model was preferred by $\mathrm{R}^{2}$ (Paine et al., 2012). However, a different result was observed based on a previous study in which the growth results of Spirulina platensis fitted well with the Logistic rate equation (Zeng et al., 2012). The variation in results can be due to differences in microalgae strains, growth medium, cultivation conditions and mode of cultivation (Lammers et al., 2017). 


\section{CONCLUSION}

This present study concluded that the maximum biomass concentration of Halochlorella rubescens was $0.49 \pm 0.01 \mathrm{~g} / \mathrm{L}$ using $\mathrm{pH} 10.00$ as initial cultivation $\mathrm{pH}$ and supplied with $5 \% \quad \mathrm{CO}_{2}$ concentration $(\mathrm{v} / \mathrm{v})$. Apart from that, there is the potential of Halochlorella rubescens microalgae to accumulate high carbohydrate productivity up to $22.42 \mathrm{mg} / \mathrm{L}$.d under this condition and to be feasible for the production of chemical and biofuel. This study clearly indicated that $\mathrm{pH}$ and $\mathrm{CO}_{2}$ play a significant role in the growth of microalgae and carbohydrate biosynthesis. In addition, FTIR spectroscopy can be used to monitor qualitative changes in biochemical compound under elevated conditions. Determination of microalgae kinetic growth model has been performed and it can be concluded that the Gompertz model with an $\mathrm{R}^{2}$ value of 0.9977 is the most appropriate model for understanding and determining Halochlorella rubescens growth under elevated conditions. This information is useful for the prediction of the growth characteristics of microalgae and could act as an essential platform when the cultivation is expanded to commercial use.

\section{ACKNOWLEDGEMENTS}

The authors wish to thank School of Industrial Technology, Universiti Sains Malaysia and the Ministry of Higher Education, Malaysia (USM). The project and manuscript preparation were financially supported by the RUI Grant 1001/PTEKIND/ 8011043 and USM Fellowship RU(1001/CIPS/ AUPE001) from Universiti Sains Malaysia.

\section{REFERENCES}

Al-Safaar, A.T., Al-Rubiaee, G.H. \& Salman, S.K. 2016. Effect of $\mathrm{pH}$ condition on the growth and lipid content of microalgae Chlorella vulgaris \& Chroococcus minor. Journal of Scientific \& Engineering Research, 7(11): 1139.

Béchet, Q., Laviale, M., Arsapin, N., Bonnefond, H. \& Bernard, O. 2017. Modeling the impact of high temperatures on microalgal viability and photosynthetic activity. Biotechnology for Biofuels, 10(1): 136.

Benedetti, M., Vecchi, V., Barera, S. \& Dall'Osto, L. 2018. Biomass from microalgae: the potential of domestication towards sustainable biofactories. Microbial Cell Factories, 17(1): 173.
Blinová, L., Bartošová, A. \& Gerulová, K. 2015. Cultivation of microalgae (Chlorella vulgaris) for biodiesel production. Research Papers Faculty of Materials Science and Technology Slovak University of Technology, 23(36): 87-95.

Caporgno, M.P. \& Mathys, A. 2018. Trends in microalgae incorporation into innovative food products with potential health benefits. Frontiers in Nutrition, 5: 58.

Chen, C.Y., Zhao, X.Q., Yen, H.W., Ho, S.H., Cheng, C.L., Lee, D.J., Bai, F.W. \& Chang, J.S. 2013. Microalgae-based carbohydrates for biofuel production. Biochemical Engineering Journal, 78: $1-10$.

Chinnasamy, S., Ramakrishnan, B., Bhatnagar, A. \& Das, K.C. 2009. Biomass production potential of a wastewater alga Chlorella vulgaris ARC 1 under elevated levels of $\mathrm{CO}_{2}$ and temperature. International Journal of Molecular Science, 10(2): 518-532.

Cortés, A.A., Sánchez-Fortún, S., García, M. \& Bartolomé, M.C. 2018. Effects of $\mathrm{pH}$ on the growth rate exhibited of the wild-type and Cd-resistant Dictyosphaerium chlorelloides strains. Limnetica, 37(2): 229-238.

Darvehei, P., Bahri, P.A. \& Moheimani, N.R. 2018. Model development for the growth of microalgae: a review. Renewable and Sustainable Energy Reviews, 97: 233-258.

Driver, T., Bajhaiya, A.K., Allwood, J.W., Goodacre, R., Pittman, J.K. \& Dean, A.P. 2015. Metabolic responses of eukaryotic microalgae to environmental stress limit the ability of FT-IR spectroscopy for species identification. Algal Research, 11: 148-155.

Dubinsky, Z., Falkowski, P.G. \& Wyman, K. 1986. Light harvesting and utilization by phytoplankton. Plant and Cell Physiology, 27(7): 1335-1349.

Eroglu, E., Eggers, P.K., Winslade, M., Smith, S.M. \& Raston, C.L. 2013. Enhanced accumulation of microalgal pigments using metal nanoparticle solutions as light filtering devices. Green Chemistry, 15(11): 3155-3159.

Fan, J., Ning, K., Zeng, X., Luo, Y., Wang, D., Hu, J., Li, J., Xu, H., Huang, J., Wan, M., Wang, W., Zhang, D., Shen, G., Run, C., Liao, J., Fang, L., Huang, S., Jing, X., Su, X., Wang, A., Bai, L., H, Z.M., Xu, J. \& Li, Y. 2015. Genomic foundation of starch-to-lipid switch in oleaginous Chlorella spp. Plant Physiology, 169(4): 2444-61.

Filali, R., Tebbani, S., Dumur, D., Isambert, A., Pareau, D. \& Lopes, F. 2011. Growth modeling of the green microalga Chlorella vulgaris in an air-lift photobioreactor. IFAC Proceedings Volumes, 44(1): 10603-10608. 
Gong, J. \& You, F. 2014. Value-added chemicals from microalgae: greener, more economical, or both? ACS Sustainable Chemistry \& Engineering, 3(1): 82-96.

Han, F., Huang, J., Li, Y., Wang, W., Wan, M., Shen, G. \& Wang, J. 2013. Enhanced lipid productivity of Chlorella pyrenoidosa through the culture strategy of semi-continuous cultivation with nitrogen limitation and $\mathrm{pH}$ control by $\mathrm{CO}_{2}$. Bioresource Technology, 136: 418-424.

Ho, S.H., Chen, C.Y. \& Chang, J.S. 2012. Effect of light intensity and nitrogen starvation on $\mathrm{CO}_{2}$ fixation and lipid/carbohydrate production of an indigenous microalga Scenedesmus obliquus CNW-N. Bioresource Technology, 113: 244252.

Ji, M.K., Yun, H.S., Hwang, J.H., Salama, E.S., Jeon, B.H. \& Choi, J. 2017. Effect of flue gas $\mathrm{CO}_{2}$ on the growth, carbohydrate and fatty acid composition of a green microalga Scenedesmus obliquus for biofuel production. Environmental Technology, 38(16): 2085-2092.

Kassim, M.A., Rashid, M.A. \& Halim, R. 2017. Towards biorefinery production of microalgal biofuels and bioproducts: production of acetic acid from the fermentation of Chlorella sp. and Tetraselmis suecica hydrolysates. Green and Sustainable Chemistry, 7(2): 152-171.

Khairy, H.M., Shaltout, N.A., El-Naggar, M.F. \& ElNaggar, N.A. 2014. Impact of elevated $\mathrm{CO}_{2}$ concentrations on the growth and ultrastructure of non-calcifying marine diatom (Chaetoceros gracilis F. Schütt). The Egyptian Journal of Aquatic Research, 40(3): 243-250.

Kroumov, A.D., Módenes, A.N., Trigueros, D.E.G., Espinoza-Quiñones, F.R., Borba, C.E., Scheufele, F.B. \& Hinterholz, C.L. 2016. A systems approach for $\mathrm{CO}_{2}$ fixation from flue gas by microalgae - Theory review. Process Biochemistry, 51(11): 1817-1832.

Lam, M.K., Lee, K.T., Khoo, C.G., Uemura, Y. \& Lim, J.W. 2016. Growth kinetic study of Chlorella vulgaris using lab-scale and pilot-scale photobioreactor: effect of $\mathrm{CO}_{2}$ concentration. Journal of Engineering and Science Techno$\log y, 7:$ 73-87.

Lammers, P.J., Huesemann, M., Boeing, W., Anderson, D.B., Arnold, R.G., Bai, X., Bhole, M., Brhanavan, Y., Brown, L. \& Brown, J. 2017. Review of the cultivation program within the national alliance for advanced biofuels and bioproducts. Algal Research, 22: 166-186.

Last, G.V. \& Schmick, M.T. 2011. Identification and selection of major carbon dioxide stream compositions. United State Department of Energy, 1-19.
Lee, E., Jalalizadeh, M. \& Zhang, Q. 2015. Growth kinetic models for microalgae cultivation: A review. Algal Research, 12: 497-512.

Li, T., Xu, J., Wu, H., Jiang, P., Chen, Z. \& Xiang, W. 2019. Growth and biochemical composition of Porphyridium purpureum SCS-02 under different nitrogen concentrations. Marine drugs, 17(2): 124.

Lise, A., Per, M. \& Hansen, J. 2007. Direct effects of $\mathrm{pH}$ and inorganic carbon on macroalgal photosynthesis and growth. Marine Biology Research, 3(3): 134-144.

Lu, L., Yang, G., Zhu, B. \& Pan, K. 2017. A comparative study on three quantitating methods of microalgal biomass. Indian Journal of Geo Marine Sciences, 46(11): 2265-2272.

Lv, J.M., Cheng, L.H., Xu, X.H., Zhang, L. \& Chen, H.L. 2010. Enhanced lipid production of Chlorella vulgaris by adjustment of cultivation conditions. Bioresource Technology, 101(17): 6797-6804.

Moroney, J.V. \& Ynalvez, R.A. 2007. Proposed carbon dioxide concentrating mechanism in Chlamydomonas reinhardtii. Eukaryotic Cell, 6(8): 1251-1259.

Mousavi, S., Najafpour, G.D. \& Mohammadi, M. 2018. $\mathrm{CO}_{2}$ bio-fixation and biofuel production in an airlift photobioreactor by an isolated strain of microalgae Coelastrum sp. SM under high $\mathrm{CO}_{2}$ concentrations. Environmental Science and Pollution Research, 25(30): 30139-30150.

Murdock, J.N. \& Wetzel, D.L. 2009. FT-IR microspectroscopy enhances biological and ecological analysis of algae. Applied Spectroscopy Reviews, 44(4): 335-361.

Mussgnug, J.H., Klassen, V., Schlüter, A. \& Kruse, O. 2010. Microalgae as substrates for fermentative biogas production in a combined biorefinery concept. Journal of Biotechnology, 150(1): $51-56$.

Nielsen, S.S. 2010. Phenol-sulfuric acid method for total carbohydrates. Food Analysis Laboratory Manual, 47-53.

Paine, C., Marthews, T.R., Vogt, D.R., Purves, D., Rees, M., Hector, A. \& Turnbull, L.A. 2012. How to fit nonlinear plant growth models and calculate growth rates: an update for ecologists. Methods in Ecology and Evolution, 3(2): 245256.

Pires, J., Alvim-Ferraz, M., Martins, F. \& Simões, M. 2012. Carbon dioxide capture from flue gases using microalgae: engineering aspects and biorefinery concept. Renewable and Sustainable Energy Reviews, 16(5): 3043-3053. 
Posadas, E., del Mar Morales, M., Gomez, C., Acién, F.G. \& Muñoz, R. 2015. Influence of $\mathrm{pH}$ and $\mathrm{CO}_{2}$ source on the performance of microalgaebased secondary domestic wastewater treatment in outdoors pilot raceways. Chemical Engineering Journal, 265: 239-248.

Praveen, K., Abinandan, S., Natarajan, R. \& Kavitha, M. 2018. Biochemical responses from biomass of isolated Chlorella sp., under different cultivation modes: non-linear modelling of growth kinetics. Brazilian Journal of Chemical Engineering, 35(2): 489-496.

Qiu, R., Gao, S., Lopez, P.A. \& Ogden, K.L. 2017. Effects of $\mathrm{pH}$ on cell growth, lipid production and $\mathrm{CO}_{2}$ addition of microalgae Chlorella sorokiniana. Algal Research, 28: 192-199.

Rosenberg, J.N., Mathias, A., Korth, K., Betenbaugh, M.J. \& Oyler, G.A. 2011. Microalgal biomass production and carbon dioxide sequestration from an integrated ethanol biorefinery in Iowa: A technical appraisal and economic feasibility evaluation. Biomass and Bioenergy, 35(9): 3865-3876.

Sahoo, D., Elangbam, G. \& Devi, S.S. 2012. Using algae for carbon dioxide capture and bio-fuel production to combat climate change. Journal of the Phycological Society, 42(1): 32-38.

Salih, F.M. 2011. Microalgae tolerance to high concentrations of carbon dioxide: A review. Journal of Environmental Protection, 2(05): 648.

Tang, D., Han, W., Li, P., Miao, X. \& Zhong, J. 2011. $\mathrm{CO}_{2}$ biofixation and fatty acid composition of Scenedesmus obliquus and Chlorella pyrenoidosa in response to different $\mathrm{CO}_{2}$ levels. Bioresource Technology, 102(3): 3071-3076.

Taraldsvik, M. \& Myklestad, S.M. 2000. The effect of $\mathrm{pH}$ on growth rate, biochemical composition and extracellular carbohydrate production of the marine diatom Skeletonema costatum. European Journal of Phycology, 35(2): 189-194.

Teoh, M.L., Wong, C.Y. \& Phang, S.M. 2013. Effect of increased $\mathrm{CO}_{2}$ and temperature on growth, photosynthesis and lipid content of tropical algae. Malaysian Journal of Science, 32: 85-94.

Vaquero, I., Vázquez, M., Ruiz-Domínguez, M. \& Vílchez, C. 2014. Enhanced production of a lutein-rich acidic environment microalga. Journal of applied Microbiology, 116(4): 839850.
Vidyashankar, S., Deviprasad, K., Chauhan, V., Ravishankar, G. \& Sarada, R. 2013. Selection and evaluation of $\mathrm{CO}_{2}$ tolerant indigenous microalga Scenedesmus dimorphus for unsaturated fatty acid rich lipid production under different culture conditions. Bioresource Technology, 144: 28-37.

Widjaja, A. 2010. Lipid production from microalgae as a promising candidate for biodiesel production. Makara Journal of Technology, 13(1): 47-51.

Yang, J., Rasa, E., Tantayotai, P., Scow, K.M., Yuan, H. \& Hristova, K.R. 2011. Mathematical model of Chlorella minutissima UTEX2341 growth and lipid production under photoheterotrophic fermentation conditions. Bioresource Technology, 102(3): 3077-3082.

Yang, Y. \& Gao, K. 2003. Effects of $\mathrm{CO}_{2}$ concentrations on the freshwater microalgae, Chlamydomonas reinhardtii, Chlorella pyrenoidosa and Scenedesmus obliquus (Chlorophyta). Journal of Applied Phycology, 15(5): 379-389.

Ying, K., D, J.G. \& Zimmerman, W.B. 2014. Effects of $\mathrm{CO}_{2}$ and $\mathrm{pH}$ on growth of the microalga Dunaliella salina. Journal of Microbial \& Biochemical Technology, 6(3): 167-173.

Yu, X.J., Huang, C.Y., Chen, H., Wang, D.S., Chen, J.L., Li, H.J., Liu, X.Y., Wang, Z., Sun, J. \& Wang, Z.P. 2019. High-throughput Biochemical fingerprinting of oleaginous Aurantiochytrium $\mathrm{sp}$. strains by fourier transform infrared spectroscopy (FT-IR) for lipid and carbohydrate productions. Molecules, 24(8): 1593.

Zeng, X., Danquah, M.K., Zhang, S., Zhang, X., Wu, M., Chen, X.D., Ng, I.S., Jing, K. \& Lu, Y. 2012. Autotrophic cultivation of Spirulina platensis for $\mathrm{CO}_{2}$ fixation and phycocyanin production. Chemical Engineering Journal, 183: 192-197.

Zhang, D., Dechatiwongse, P., del Rio-Chanona, E., Maitland, G., Hellgardt, K. \& Vassiliadis, V.S. 2015. Modelling of light and temperature influences on cyanobacterial growth and biohydrogen production. Algal Research, 9: 263-274. 
